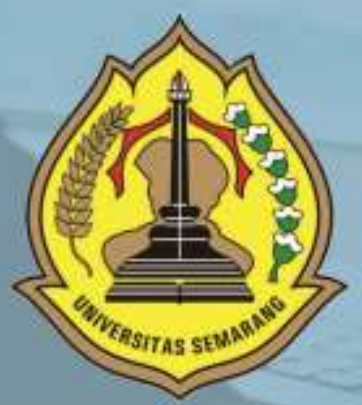

P-ISSN: 1412-5331, E-ISSN: 2716-2532 MAJALAH ILMIAH FAKULTAS EKONOMI UNIVERSITAS SEMARANG

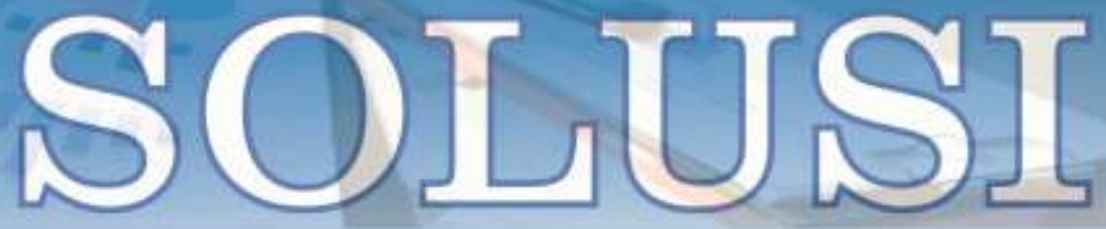

PENGARUH TINGKAT LITERASI KEUANGAN, SIKAP INDIVIDU TERHADAP MINAT INVESTASI SAHAM DI KALANGAN MAHASISWA S2 MAGISTER MANAJEMEN UNIVERSITAS SEMARANG (Asah Wiari Sidiq: Asih Niati - Universitas Semarang)

PENINGKATAN KINERJA PENGAJARAN DOSEN MELALUI KEPEMIMPINAN TRANSFORMASIONAL DAN PEMENUHAN KEBUTUHAN PSIKOLOGIS DASAR DENGAN PEMEDIASI MOTIVASI KER.JA (Anik Herminingsih - Universitas Mercu Buana)

PENGARUH PAJAK, TUNNELING INCENTIVE DAN GOOD CORPORATE GOVERNANCE (GCG) DAN MEKANISME BONUS TERHADAP INDIKASI TRANSFER PRICING PADA PERUSAHAAN MANUFAKTUR (Arum Sasi Andayani; Andiani Ika Sulistyanuati - Liniversitas Semarang)

PENGELOLAAN ALOKASI DANA DESA: AKUNTABILITAS DAN TRANSPARANSI (STUDI KASUS PADA DESA GINGGANGTANI, KECAMATAN GUBUG, KABUPATEN GROBOGAN) (Ana Rokhatt: Saifidin: Dian Trivani - Universitas Semarang)

PENERAPAN STRATEGI BAURAN PEMASARAN PADA USAHA KECIL TELUR ASIN DI KELURAHAN TEGAL SARI, KECAMATAN CANDI SARI, SEMARANG (Nisa Novia Avien Christy; Dwi Widi Pratito - Universitas Semarang)

FAKTOR-FAKTOR YANG MEMPENGARUHI PROFITABILITAS LEMBAGA PERKREDITAN DESA (LPD) DI KABUPATEN BADUNG (Ida Ayu Nyoman Yuliastuti, Putu Kepramareni, I Gusti Ayu Asta Yunisari - Universitas Mahasaraswati Denpasar)

KEBERHASILAN MEMPERTAHANKAN WARUNG MAKAN PRASMANAN MBAH SAN (Sri Wulandari: Susanto - Universitas Semarang)

BRAND PERSONALITY DAN GENDER BRAND PERSONALITY STRATEGI MEMBANGUN MEREK (Haris Murwanto - Universitas Semarang)

POLA PERMINTAN DAN PENAWARAN KETERSEDIAAN DAGING SAPI NASIONAL TAHUN 2030 DENGAN PENDEKATAN FORECASTING (Moeljono - Universitas Semarang)

PENGARUH BRAND IMAGE, KUALITAS PRODUK, PERSEPSI HARGA TERHADAP KEPUTUSAN PEMBELIAN (STUDI KASUS PADA PRODUK SUSU NATURSOYA CV. GLOBAL MANDIRI SEJAHTERA KANCA PURWODADI)

(Ajeng Ayr Fatimah P: Soedarmadi - Untversitas Semarang) 


\section{DESKRIPSI}

Majalah IImiah Solusi Mengkaji

Masalah-Masalah Sosial,

Ekonomi dan Bisnis

\section{KETERANGAN TERBIT}

Terbit Pertama Kali Juli 2002

dan SelanjutnyaTerbit Tiga Bulan

Sekali (Januari, April, Juli dan

Oktober)

\section{PENERBIT}

Fakultas Ekonomi USM

\section{ALAMAT PENERBIT}

JL. Soekarno Hatta Semarang

Telp. 024-6702757 Fax. 024-6702272

\section{PENGELOLA}

Editor in Chief : Yohanes Suhardjo, SE, M.Si., Ak, CA Vice Editor Chief : Sugeng Rianto, SE, MM

Managing Editor: Edy Suryawardana, SE, MM

Secretary of Managing Editor : Asih Niati, SE, MM

Administration \& Circulation :

Citra Rizkiana, SE, MM

Layout \& Typesetting : M Burhan Hanif S.Kom, M.Kom

Board of Editors:

1. Prof. Dr. Ir. Kesi Widjajanti, SE, MM (USM)

2. Prof. Drs. Mohammad Nasir, Msi, Ph.D, AK. (USM)

3. Prof. Supramono SE, MBA, DBA (UKSW)

4. Prof. Drs. H. Imam Ghozali, M.Com, Akt, PhD (UNDIP)

5. Prof. Dr. Agus Suroso, MS (UNSOED)

6. Prof. Dr. Widodo, SE, M.Si (UNISSULA)

7. Prof. Dr. Dra. Sulastri, ME, M.Kom (UNSRI)

8. Dr. Ardiani Ika S, SE, MM, Ak, CA, CPA (USM)

\section{KATA PENGANTAR}

Sungguh merupakan kebahagiaan tersendiri bagi kami, takala kami dapat hadir rutin setiap tiga bulan sekali untuk saling bertukar pikiran mengenai hal-hal baru dibidang sosial, ekonomi dan bisnis.

Pada kesempatan ini penerbit menyampaikan terima kasih kepada semua pihak yang telah mengirimkan artikel-artikelnya. Penerbit akan membuka kesempatan seluas-luasnya bagi seluruh kalangan akademisi maupun praktisi baik dari dalam maupun luar Universitas Semarang untuk mempublikasikan karya ilmiahnya.

Penerbitan majalah ilmiah "SOLUSI" kali ini menghadirkan 10 (Sepuluh) artikel yang kami anggap layak untuk diterbitkan, dengan harapan dapat menjadi tambahan referensi bagi para pembaca dan menjadi sumbangan pengembangan persemaian khasanah pengetahuan dibidang sosial, ekonomi dan bisnis.

Akhir kata semoga majalah ilmiah "SOLUSI" dapat memberi manfaat yang sebesar-besarnya.

Hormat Kami 


\section{DAFTAR ISI}

PENGARUH TINGKAT LITERASI KEUANGAN, SIKAP INDIVIDU

TERHADAP MINAT INVESTASI SAHAM DI KALANGAN MAHASISWA S2 MAGISTER MANAJEMEN UNIVERSITAS SEMARANG

(Asah Wiari Sidiq; Asih Niati - Universitas Semarang).......

PENINGKATAN KINERJA PENGAJARAN DOSEN MELALUI

KEPEMIMPINAN TRANSFORMASIONAL DAN PEMENUHAN KEBUTUHAN PSIKOLOGIS DASAR DENGAN PEMEDIASI MOTIVASI KERJA

(Anik Herminingsih - Universitas Mercu Buana)

PENGARUH PAJAK, TUNNELING INCENTIVE DAN GOOD CORPORATE GOVERNANCE (GCG) DAN MEKANISME BONUS TERHADAP INDIKASI TRANSFER PRICING PADA PERUSAHAAN MANUFAKTUR

(Arum Sasi Andayani; Ardiani Ika Sulistyawati - Universitas Semarang)

PENGELOLAAN ALOKASI DANA DESA: AKUNTABILITAS DAN TRANSPARANSI

(STUDI KASUS PADA DESA GINGGANGTANI, KECAMATAN GUBUG, KABUPATEN GROBOGAN)

(Ana Rokhati; Saifudin; Dian Triyani - Universitas Semarang).

PENERAPAN STRATEGI BAURAN PEMASARAN PADA USAHA KECIL TELUR ASIN DI KELURAHAN TEGAL SARI, KECAMATAN CANDI SARI, SEMARANG

(Nisa Novia Avien Christy; Dwi Widi Pratito - Universitas Semarang)

FAKTOR-FAKTOR YANG MEMPENGARUHI PROFITABILITAS LEMBAGA PERKREDITAN DESA (LPD) DI KABUPATEN BADUNG

(Ida Ayu Nyoman Yuliastuti; Putu Kepramareni; I Gusti Ayu Asta Yunisari - Universitas Mahasaraswati Denpasar)..... .75

KEBERHASILAN MEMPERTAHANKAN WARUNG MAKAN PRASMANAN MBAH SAN

(Sri Wulandari; Susanto - Universitas Semarang).....

BRAND PERSONALITY DAN GENDER BRAND PERSONALITY STRATEGI MEMBANGUN MEREK

(Haris Murwanto - Universitas Semarang).

POLA PERMINTAN DAN PENAWARAN KETERSEDIAAN DAGING SAPI NASIONAL TAHUN 2030 DENGAN PENDEKATAN FORECASTING

(Moeljono - Universitas Semarang)......

PENGARUH BRAND IMAGE, KUALITAS PRODUK, PERSEPSI HARGA TERHADAP KEPUTUSAN PEMBELIAN (STUDI KASUS PADA PRODUK SUSU NATURSOYA CV. GLOBAL MANDIRI SEJAHTERA KANCA PURWODADI)

(Ajeng Ayu Fatimah P; Soedarmadi - Universitas Semarang) 


\title{
PENERAPAN STRATEGI BAURAN PEMASARAN PADA USAHA KECIL TELUR ASIN DI KELURAHAN TEGAL SARI, KECAMATAN CANDI SARI, SEMARANG
}

\author{
Nisa Novia Avien Christy ${ }^{1}$ \\ Dwi Widi Pratito ${ }^{2}$
}

\author{
Nisachristy971@gmail.com ${ }^{1}$ \\ titopratito@usm.ac.id²
}

Fakultas Ekonomi Universitas Semarang

Diterima: November 2019, Disetujui:Desember 2019,Dipublikasikan: Januari 2020

\begin{abstract}
Business competition that occurs increasingly competitive requires business actors to pay attention to efficiency and effectiveness in the use of available resources so that the goals set by the company are achieved. One factor supporting the success of a company is achieved is the company has the right marketing strategy. Marketing activities in essence focus on the product, application of prices, distribution policies and ways of promotion, which in this case is known as the marketing mix. Marketing activities certainly require a strategy. This strategy must certainly be able to contribute to the achievement of company goals, namely improving the quality and breadth of marketing networks

The purpose of this study was to determine the application of the marketing mix carried out by the marketing of salted eggs and sales techniques in the marketing of salted eggs.

The purpose of this study was to determine the application of the marketing mix carried out by salted egg entrepreneurs and sales techniques in the marketing of salted eggs. This research uses descriptive analysis, with data collection techniques through interviews and observations. The sampling technique uses a purposive method. The sample in this study amounted to 4 (four) respondents who are small entrepreneurs salted eggs in the area of Tegal Sari who are members of the MSME Mekarsari

The results of this study are that the application of the Semarang Salted Egg marketing mix strategy is not optimal. The Semarang Salted Egg Business still uses traditional marketing techniques. While the techniques of sales techniques carried out by salted egg entrepreneurs include: 1) Personal selling techniques (in this case with mobile sales), 2) Sales techniques with special identities (attributes and call language), and 3) Price cutting techniques (price cuts for regular customers and in large quantities.
\end{abstract}

Keywords: marketing mix, entrepeneurs, sales techniques.

\begin{abstract}
ABSTRAK
Persaingan usaha yang terjadi semakin kompetitif menuntut para pelaku usaha agar memperhatikan efisiensi dan efektifitas dalam penggunaan sumber daya yang dimiliki agar tujuan yang ditetapkan perusahaan tersebut tercapai. Salah satu faktor pendukung keberhasilan suatu perusahaan tercapai adalah perusahaan mempunyai strategi pemasaran yang tepat. Kegiatan pemasaran pada intinya memfokuskan diri pada produk, penerapan harga, kebijakkan distribusi dan cara promosi, yang dalam hal ini dikenal sebagai bauran pemasaran. Kegiatan pemasaran tentunya membutuhkan suatu strategi. Strategi ini tentu harus mampu memberikan kontribusi terhadap pencapaian tujuan perusahaan yaitu peningkatan mutu dan luasnya jaringan pemasaran

Tujuan penelitian ini untuk mengetahui penerapan bauran pemasaran yang dilakukan oleh pengusaha telur asin dan Teknik penjualan dalam pemasaran telur asin. Penelitian ini menggunakan
\end{abstract}


analisis deskriptif, dengan teknik pengumpulan data melalui wawancara dan observasi. Teknik pengambilan sampel menggunakan metode purposive. Sampel dalam penelitian ini berjumlah 4 (empat) responden yang merupakan pengusaha kecil telur asin di wilayah Tegal Sarii yang masuk menjadi anggota UMKM Mekarsari

Hasil dari penelitian ini adalah Penerapan strategi bauran pemasaran Telur Asin Semarang belum optimal. Usaha Telur Asin semarang tersebut masih menggunakan teknik pemasaran tradisional. Sedangkan Teknik Teknik penjualan yang dilakukan oleh pengusaha telur asin meliputi: 1)Teknik personal selling (dalam hal ini dengan penjualan keliling), 2) Teknik penjualan dengan identitas khusus (atribut dan bahasa panggilan), dan 3)Teknik pemotongan harga (pemotongan harga bagi pelanggan tetap dan dalam jumlah banyak.

Kata Kunci : bauran pemasaran, pelaku usaha, Teknik penjualan..

\section{PENDAHULUAN}

Persaingan usaha yang terjadi semakin kompetitif menuntut para pelaku usaha agar memperhatikan efisiensi dan efektifitas dalam penggunaan sumber daya yang dimiliki agar tujuan yang ditetapkan perusahaan tersebut tercapai. Salah satu faktor pendukung keberhasilan suatu perusahaan tercapai adalah perusahaan mempunyai strategi pemasaran yang tepat. Kegiatan pemasaran pada intinya memfokuskan diri pada produk, penerapan harga, kebijakkan distribusi dan cara promosi, yang dalam hal ini dikenal sebagai bauran pemasaran. Kegiatan pemasaran tentunya membutuhkan suatu strategi. Strategi ini tentu harus mampu memberikan kontribusi terhadap pencapaian tujuan perusahaan yaitu peningkatan mutu dan luasnya jaringan pemasaran. Bauran pemasaran (marketing mix) adalah strategi pemasaran untuk menggunakan dan mengefektifkan produk, periklanan, harga, saluran distribusi, dan unsur-unsur lain. Salah satu cara untuk mengetahui dan mengidentifikasi sebuah keberhasilan dalam pemasaran yaitu dengan bauran pemasaran.

Agar usaha telur asin ini dapat memperluas pangsa pasar dan merebut pasar, maka usaha tersebut perlu mengetahui strategi bauran pemasaran atau tataniaga campuran (marketing mix) yang diperlukan untuk meningkatkan volume penjualan. Bauran pemasaran merupakan kombinasi antara empat unsur pemasaran, yakni produk, harga, promosi dan saluran distribusi, yang merupakan komponen yang dapat dikendalikan dan dapat digunakan oleh perusahaan untuk mepengaruhi tanggapan atau respon konsumen. Oleh karena itu, para pengusaha perlu mengetahui bagaimana kombinasi bauran pemasaran (marketing mix) yang tepat untuk diterapkan agar dapat menarik konsumen atau pelanggan sebanyak mungkin, sehingga memperoleh keuntungan yang maksimal (Kotler, 2002). 
Penjualan sangat penting untuk menentukan kelangsungan bagi perusahaan. Penjual dituntut untuk mampu dan memiliki bakat seni serta keahlian untuk mempengaruhi orang lain. Bakat seperti ini yang sering tidak dimiliki oleh setiap orang karena tidak mudah untuk mengarahkan kemauan calon pembeli dengan cara mengemukakan berbagai alasan serta pendapatnya. Tanpa kesuksesan dalam penjualan sudah dapat dipastikan bahwa perusahaan itu tidak akan mampu bertahan dan dinamis lagi, karena tidak ada pemasukan yang digunakan untuk melakukan produksi.

Salah satu perusahaan yang menggunakan teori bauran pemasaran dan teknikteknik penjualan adalah usaha produsen telur asin yang ada di Kelurahan Tegal sari, Kecamatan Candisari, Semarang. Berkembang dan tidaknya sebuah perusahaan dapat dilihat melalui perumusan marketing mix secara efektif.

\section{TELAAH LITERATUR}

\section{Pemasaran}

Pemasaran disebut juga tataniaga karena istilah niaga yang berarti dagang yang biasanya dijalankan melalui pasar untuk menyampaikan suatu produk atau jasa dari produsen ke konsumen. Tataniaga merupakan kegiatan dan usaha yang berhubungan dengan perpindahan hak milik dan fisik barang-barang hasil pertanian dari produsen ke konsumen yang termasuk didalamnya kegiatan-kegiatan tertentu yang menghasilkan perubahan-perubahan bentuk dari barang yang ditujukan untuk mempermudah penyaluran dan memberikan kepuasan yang lebih tinggi kepada konsumen (Limbong dan Sitorus, 1987 dalam Ivan 2009). Lebih lanjut lagi menurut American Marketing Association (AMA) mendefinisikan pemasaran adalah fungsi organisasi dan serangkaian proses untuk menciptakan, mengomunikasikan dan memberikan nilai kepada pelanggan dan untuk mengelola hubungan pelanggan dengan cara yang menguntungkan organisasi dan pemangku kepentingannya (Kotler 2009).

\section{Manajemen Pemasaran}

Menurut Kotler (2004) manajemen pemasaran adalah penganalisaan, perencanaan, pelaksanaan, dan pengawasan program-program yang ditujukan untuk mengadakan pertukaran dengan pasar yang dituju untuk mencapai tujuan organisasi. Tugas yang diperlukan untuk manajemen yang sukses antara lain adalah 
mengembangkan strategi dan rencana pemasaran, menangkap pemahaman pemasaran, berhubungan dengan pelanggan, membangun merek yang kuat, membentuk penawaran pasar, menghantarkan nilai, mengkomunikasikan nilai serta menciptakan pertumbuhan jangka Panjang.

\section{Strategi Pemasaran}

Menurut Tjiptono (2008) strategi pemasaran merupakan rencana yang menjabarkan ekspektasi perusahaan akan dampak dari berbagai aktivitas atau program pemasaran terhadap permintaan produk atau lini produknya di pasar sasaran tertentu. Strategi pemasaran merupakan bagian internal dari strategi bisnis yang akan memberikan arah pada semua fungsi manajemen suatu organisasi dalam kaitannya dengan variabel-variabel seperti segmentasi pasar, identifikasi pasar sasaran positioning, elemen dan biaya bauran pemasaran.

\section{Product}

Produk menurut Tjiptono (2009:95) adalah pemahaman subjektif dari produsen atas 'sesuatu' yang bisa ditawarkan sebagai usaha untuk mencapai tujuan organisasi melalui pemenuhan kebutuhan dan keinginan konsumen, sesuai dengan kompetensi dan kapasitas organisasi serta daya beli pasar..

\section{Price}

Harga merupakan salah satu atribut yang akan menentukan jumlah permintaan konsumen (pelanggan). Jika nilainya meningkat, hal ini berarti juga bahwa manfaat yang dirasakan konsumen meningkat. Volume penjualan ditentukan oleh keputusan pemasaran dalam menentukan harga produk, sehingga perusahaan harus menetapkan suatu harga dengan baik agar harga tersebut mampu menutupi semua biaya produksi serta lebih dari itu untuk mendapatkan keuntungan yang akan diperoleh perusahaan serta penentu bagi keberlangsungan perusahaan dalam pasar. Strategi penetapan harga dapat dijadikan perusahaan untuk bersaing dengan para pesaing dengan melihat mutu atau kualitas dan harga produk.

Harga adalah sejumlah uang (ditambah beberapa produk kalau mungkin) yang ditambahkan untuk mendapatkan sejumlah kombinasi dari produk dan pelayanannya. 
(Widiana, 2010:59). Faktor-faktor yang mempengaruhi tingkat harga menurut Swastha dalam Widiana (2010): (1) Kondisi perekonomian, (2) Penawaran dan permintaan, (3) Elastisitas permintaan, (4) Persaingan, (5) Biaya, dam (6) Pengawasan pemerintah.

\section{Promotion}

Menurut Tjiptono (2000) promosi merupakan salah satu faktor penentu keberhasilan suatu program pemasaran. Menurut Kotler dan Amstrong (2008:116) bauran promosi (promotion mix) disebut juga bauran komunikasi pemasaran (marketing communication mix). Bauran promosi: (1) Periklanan (advertising), (2) Promosi penjualan (sales promotion), (3) Hubungan masyarakat (public relations), (4) Penjualan personal (personal selling), (5) Pemasaran langsung (direct marketing)

\section{Place}

Menurut Tjiptono (2000:185) pendistribusian dapat diartikan sebagai kegiatan pemasaran yang berusaha memperlancar dan mempermudah penyampaian barang dan jasa dari produsen kepada konsumen sehingga penggunaannya sesuai dengan yang diperlukan (jenis, jumlah, harga, tempat dan saat dibutuhkan). Menurut Swastha dan Irawan (1997:295-297) terdapat berbagai macam saluran distribusi barang konsumsi, diantaranya: (1) Produsen-Konsumen, (2) Produsen-Pengecer-Konsumen, (3) ProdusenPedagang Besar-Pengecer-Konsumen, (4) Produsen-Agen-Pengecer-Konsumen, dan (5) Produsen-Agen-Pedagang Besar-Pengecer Konsumen.

\section{METODE PENELITIAN}

Penelitian ini dilakukan dengan cara survei dengan instrumen pengumpul data berupa Interview, Participant Observation, Document Record dan metode analisis data berupa Data Reduction, Deskripsi, Interpretasi. Populasi dalam penelitian ini adalah di Kelompok Usaha Kecil Produsen Telur Asin, Tegalsari, Semarang dengan menggunakan empat pelaku usaha sebagai informan kunci. 


\section{PEMBAHASAN}

\section{Product}

Produk yang dihasilkan oleh usaha telur asin Semarang sudah memnuhi kriteria bagian penting dalam bauran pemasaran produk, diantaranya penjagaan kualitas produk dan ciri khas produk. Di bagian lain, produksi telur asin Semarang sudah mampu memaksimalkan bagian-bagian penting laiinya dalam bauran pemasaran produk seperti:

1) Kemasan

Kemasan dalam usaha telur asin semarang ini sudah diperhatikan seperti menggunakan mika agar telur asin terlihat menarik dan mudah untuk di bawa kemana-mana. Kemasan dapat meningkatkan selera dan efisiensi bagi konsumen, bila diterapkan secara maksimal.

2) Garansi

Produk telur asin semarang mampu bertahan sampai dengan 7 hari karena kualitas, bahan dasar penyimpanan, garansi yang berupa hari(jangka wakTu) dapat diterapkan secara maksimal didalam produk telur asin ini.

3) Nama Merk

Produk telur asin ini sudah memiliki merk paten yang bernama "telur asin Semarang Den Bagoes" untuk dapat membedakan produk nya tersebut dengan produk pesaing.

\section{Price}

Pada dasarnya penentuan harga dan strategi yang dilakukan oleh pemilik usaha telur asin semarang sudah cukup baik, hanya saja akan lebih baik lagi apabila pemilik usaha Telur asin semarang juga menerapkan strategi periode pembayaran. Strategi periode pembayaran belum dilakukan secara riil oleh pemilik usaha telur asin. Meskipun dalam penerapannya memerlukan modal yang besar kerena sirkulasi uang berjalan bertahap, strategi ini mampu memberi pertimbangan yang cukup kongkrit untuk mendapatkan pelangan yang lebih banyak.

\section{Place}

Penerapan pada usaha Telur Asin Semarang menjelaskan bahwa daerah Tegalsari merupakan wilayah cukup strategis. untuk berproduksi telur asin. Faktor- 
faktor di atas yang menjadikan usaha Telur asin Semarang bertahan sampai saat ini dan bahkan cenderung berkembang. Namun masih ada beberapa faktor yang belum dikembangkan dan berjalan maksimal, diantaranya; transportasi yang belum memadai dan sering menghambat kelangsungan proses distribusi, belum adanya saluran pemasaran yang sistematis sehingga dalam distribusinya kurang maksimal karena hanya melayani konsumen tetap tidak ada perkembangan yang signifikan.

\section{Promotion}

Promosi yang dilakukan oleh pengusaha telur asin semarang yang ada di kelurahan tegalsari secara umum hanya menggunakan penjualan secara pribadi (personal selling) yang dilakukan oleh pemilik telur asin itu sendiri ataupun keluarganya, walaupun sudah ada yang menggunakan tenaga penjual namun masih terbilang minoritas. Ada beberapa hal yang perlu diperbaiki dalam promosi yang dilakukan oleh pengusaha telur asin diantaranya adalah periklanan (advertising) dan hubungan masyarakat (public relation). Dua faktor tersebut juga penting dilakukan oleh pemilik usaha telur asin karena apabila hanya mengandalkan personal selling saja, maka penjualan produk tidak akan dapat maksimal. Sehingga perlu advertising agar cakupan pemasaranya dapat disebar luaskan dan dinikmati oleh khalayak umum. Tidak kalah pentingnya membangun hubungan dengan masyarakat umum (public relation) agar terjalin hubungan yang harmonis dan ikatan yang baik dengan tujuan dapat memperluas jaringan pemasaran dan pengembangan produksi.

\section{Teknik Penjualan Telur Asin Semarang}

Adapun teknik-teknik yang dilakukan oleh penjual telur asin semarang yang ada di Kelurahan Tegalsari sebagai berikut :

1. Teknik Penjualan Personal Selling (Penjualan Keliling)

2. Teknik Penjualan dengan Identitas Khusus (Atribut dan Bahasa panggilan)

3. Teknik Pemotongan Harga (pemotongan harga bagi pelanggan tetap dan dalam jumlah banyak.

\section{KESIMPULAN}

Dari penelitian yang telah dilakukan, dapat diketahui bahwa penerapan strategi bauran pemasaran Telur Asin Semarang belum optimal. Usaha Telur Asin semarang 
tersebut masih menggunakan teknik pemasaran tradisional. Srtategi unsur-unsur 4P yang seharusnya ada masih belum bisa diterapkan, dikarenakan beberapa faktor diantarannya: kurangnya modal, transportasi yang belum memadai, minimnya jaringan. Adapun bauran pemasaran yang belum dapat diterapkan yaitu aspek harga (periode pembayaran, Daftar harga), aspek tempat (transportasi, saluran pemasaran) dan aspek promosi (advertising, public relation). Meskipun demikian Telur Asin Semarang tersebut selalu dibutuhkan oleh para konsumen, karena harganya terjangkau dan Telur Asin Semarang sudah menjadi konsumsi masyarakat Tegalsari sejak dulu. Oleh karena itu produksi Telur Asin Semarang masih bertahan dan berkembang sampai saat ini di wilayah Tegalsari dan sekitarnya.

\section{SARAN}

Untuk mengoptimalkan penerapan strategi bauran pemasaran Telur Asin Semarang dengan baik dan berdasarkan hasil analisa penulis, maka ada bebrapa saran yang perlu menjadi pertimbangan antara lain:

1. Perlu adanya peningkatan dalam penerapan bauran pemasaran $4 \mathrm{P}$ agar dalam pemasaranya dapat maksimal.

2. Lebih memvariasikan hasil produk, contohnya; telur asin tidak lagi dikukus akan tetapi bisa dengan di bakar.

3. Promosi perlu digalakkan lagi dengan jalan mengiklankan produk dan memperkuat jaringan bisnis.

\section{DAFTAR PUSTAKA}

Alamsyah, Muhammad Iqbal. 2015. Pengaruh Inovasi Produk dan Media Sosial Terhadap Brand Awareness Pada Merek Lokal Sepatu Kulit Di Bandung. Jurnal Indonesia Membangun 14 (3). 169-187

Kotler, Philip. 2000. Manajemen Pemasaran. Jilid II. Jakarta:Erlangga

Kotler, Philip dan Gary Armstrong. 2008. Prinsip-Prinsip Pemasaran, Edisi Ke-12. Jakarta:Erlangga

Rangkuti, Freddy. 2006. Analisis SWOT:Teknik Membedah Kasus Bisnis. Jakarta:Gramedia Pustaka Utama

Sugiyono. 2010. Metode Penelitian Bisnis Pendekatan Kuantitatif, Kualitatif dan R\&D. Cetakan Ke-15. Bandung:Alfabeta 
Swastha, Basudan Irawan. 1997. Manajemen Pemasaran Modern. Cetakan Kelima.

Yogyakarta:Liberty Tjiptono, Fandy. 2000. Strategi Pemasaran. Yogyakarta:Andi

Widiana, Muslichah Erma. 2010. Dasar-Dasar Pemasaran. Bandung:Karya Putra Darwati 